\title{
A adoção de Sistemas Produtivos entre Grupos de Pequenos Produtores de Algodão no Brasil ${ }^{1}$
}

\author{
Alexandre Gori Maia², Bruno César Brito Miyamoto ${ }^{3}$ e \\ José Maria Ferreira Jardim Silveira ${ }^{4}$
}

Resumo: Este trabalho analisa os padrões de produção de grupos de pequenos produtores do algodão no Brasil e seus impactos sobre as preferências declaradas por novos sistemas de produção. Especificamente, verificam-se as principais característicasque diferenciam as escolhas pelossistemas de algodão geneticamente modificado (Bt e RR) e não geneticamente modificado (colorido, orgânico e branco convencional). As análises baseiam-se em dados primários aplicados a grupos de pequenos produtores de algodão nas principais regiões produtoras no Brasil. Os padrões de associação entre as características do produtor e do sistema de produção foram analisados com a Análise de Correspondência Múltipla. A propensão a adotar novos sistemas de produção foi analisada pela Análise Conjunta. Os resultados destacam que, mesmo entre pequenos produtores, há distinções importantes entre os padrões de produção que determinam a escolha pelo tipo de semente. O conhecimento prévio do sistema de cultivo, através da prática agrícola corrente, mostra-se um fator fundamental nas preferências dos produtores por novos sistemas de produção. Conclui-se que a cadeia produtiva, principalmente o papel das cooperativas locais e das redes privadas de apoio à produção e à comercialização, teria um papel decisivo na definição de redes de influência e, consequentemente, na adoção dos sistemas produtivos.

Palavras-chaves: Transgênicos; Cotonicultura; Tecnologia agrícola; Modelo de escolhas; Análise de correspondência múltipla.

Abstract: The paper analyzes the patterns of cotton production for groups of small farmers in Brazil and its impacts on the stated preferences for new systems of production. Specifically, it identifies the main characteristics that differentiate the choices for genetically modified cotton (Bt and RR) and non-genetically modified cotton (colorful, organic and

1. Data de submissão: 7 de julho de 2015. Data de aceite: 15 de janeiro de 2016.

2. Universidade Estadual de Campinas - Instituto de Economia - Núcleo de Economia Agrícola e Ambiental. Campinas, São Paulo, Brasil. E-mail: gori@unicamp.br

3. Universidade Estadual de Campinas - Instituto de Economia - Núcleo de Economia Agrícola e Ambiental. Campinas, São Paulo, Brasil. E-mail: miyamototup@gmail.com

4. Universidade Estadual de Campinas - Instituto de Economia - Núcleo de Economia Agrícola e Ambiental. Campinas, São Paulo, Brasil. E-mail: jmsilv52@gmail.com 
conventional white). Analyses are based on primary data applied to groups of cotton farmers up to 50 hectares in the main producing regions in Brazil. The patterns of association between the characteristics of the farmers and the production systems were analyzed using Multiple Correspondence Analysis. The probability to adopt new systems of production was analyzed using the Conjoint Analysis. Results highlight that even among small farmers there are important distinctions between the patterns of production that determine the choice for new types of seed. The prior knowledge of the farming system, through the current agricultural practice, proved to be a key factor in the stated preferences for new production systems. The paper concludes that the production chain, especially the role of local cooperatives and private networks to support production and marketing, would play a central role in defining networks of influence and the adoption of production systems.

Key-words: Transgenic; Cotton production; Agricultural technology; Choice model; Multiple correspondence analysis.

Classificação JEL: C25, Q16, Q18.

\section{Introdução}

O recente desempenho produtivo da cotonicultura mato-grossense e do oeste baiano colocou o Brasil entre os maiores produtores e exportadores mundiais de algodão (BUANAIN, 2007). Nessas regiões de cerrado, a cotonicultura é praticada em grandes propriedades, com a utilização de tecnologias de fronteira do conhecimento, elevada intensidade de capital e pelo uso de sementes selecionadas de alta produtividade e adaptadas às condições de cada região (EMBRAPA, 2003).

Esse modelo de exploração intensivo em capital, que emergiu em meados dos anos 1990 e logrou uma inserção exitosa nas cadeias produtivas e no mercado externo, pouco preservou dos padrões existentes nas duas regiões que anteriormente determinavam a dinâmica da cotonicultura nacional: semiárido nordestino e região meridional (São Paulo e Paraná). Apesar das diferenças em relação às variedades de algodão cultivadas - arbórea na primeira e herbácea na segunda essas duas regiões apresentavam algumas similaridades, como a prática da cotonicultura em pequenas ou médias propriedades, elevada utilização de mão de obra e baixa intensidade de capital (GONÇALVES e RAMOS, 2008). Com o deslocamento da cotonicultura para o cerrado, a produção de algodão em pequenas propriedades se tornou quase que exclusiva de regiões marginais, desfavoráveis sob aspectos econômicos e edafoclimáticos, como o semiárido nordestino. As diferenças tecnológicas entre pequenos e grandes produtores se intensificaram, reproduzindo um fenômeno também observado em outros países em desenvolvimento, como a Argentina (ARZA et al., 2012).

As alternativas tecnológicas existentes para viabilizar a pequena produção envolveriam cadeias produtivas distintas, desde a produção até a comercialização do algodão beneficiado. Viegas (2012), por exemplo, vincula o ressurgimento do algodão por pequenos agricultores à formação de redes de comércio solidário. Esta alternativa envolve propostas de um sistema, que apesar de intensivo em mão de obra, permite aos pequenos produtores obter preços diferenciados no mercado, produzindo algodão colorido ou agroecológico. Por outro lado, a adoção de sistemas que aumentam a produtividade e reduzem a necessidade de mão de obra não seria necessariamente incompatível com a pequena produção. A busca de soluções para o manejo de ervas daninhas e insetos teria relação tanto com o aumento de eficiência dos métodos de controle quanto com a redução do uso de agroquímicos. Neste sentido, cultivares geneticamente modificados (GMs) de algodão, chamados $\mathrm{Bt}^{5}$ (resistentes a insetos) e

5. Sementes modificadas geneticamente com a introdução de genes específicos da bactéria do solo Bacillus Thruringiensis, destinados a produzir uma proteína tóxica para insetos pertencentes à ordem dos lepidópteros. 
$\mathrm{RR}^{6}$ (tolerantes a herbicidas), apareceriam como alternativas teoricamente viáveis e disponíveis aos pequenos agricultores.

Todas as alternativas foram implantadas a partir do início dos anos 2000 em várias regiões do semiárido brasileiro, incluindo o norte de Minas Gerais. Esta variedade de opções tecnológicas e de sistemas produtivos, que dependem de forma crucial da adoção pelos agricultores de determinados tipos de sementes melhoradas, motiva as questões centrais deste trabalho: por que esses sistemas produtivos convivem no espaço do semiárido? Como seriam os padrões de produção dos cotonicultores dessas regiões? Quais seriam as preferências declaradas por essas alternativas e quais seus determinantes? A caracterização dos sistemas produtivos seria um forte determinante do processo de adoção de determinadas alternativas, ou quais as razões para a existência de um hiato entre as preferências declaradas e os sistemas implementados?

Em resumo, o objetivo central do trabalho é analisar os padrões de produção dos pequenos produtores do algodão no Brasil e seus impactos sobre as preferências declaradas por tipos alternativos de sementes ou sistemas de produção. Duas contribuições principais do trabalho podem ser destacadas. Primeiro, o estudo descreve a dinâmica da cotonicultura entre pequenos produtores no Brasil e destaca como, apesar da prevalência de baixos padrões socioeconômicos e tecnológicos, haveria importantes diferenças que caracterizam os principais sistemas de produção (algodão branco convencional, algodão transgênico $\mathrm{Bt}$, algodão transgênico RR, algodão colorido e agroecológico). Segundo, investiga-se como esta diferenciação dos sistemas atuais de produção influenciaria a propensão dos produtores a adotarem novas sementes ou sistemas de produção de algodão.

6. Sementes transgênicas com a tecnologia Roundup Ready. Essa tecnologia torna as plantas tolerantes ao herbicida glifosato.

\section{Delimitação do tema e revisão da literatura}

\subsection{Um breve histórico}

As variedades de algodão colorido começaram a ser desenvolvidas pela Embrapa Algodão no início dos anos 1980, a partir de plantas encontradas em lavouras da região Nordeste (SOUZA, 2000). No entanto, a produção do algodão colorido em escala comercial teve início somente na primeira metade dos anos 2000, nos arredores do município de Patos, no estado da Paraíba, graças principalmente ao incentivo de cooperativas locais (ARAÚJO FILHO et al., 2012). Segundo Beltrão e Carvalho (2004), a maioria dos produtores cultiva o algodão colorido em áreas entre um e três hectares e chega a receber entre $30 \%$ e $40 \%$ a mais que o preço pago pelo de fibra branca, embora esses valores estejam sujeitos a frequentes flutuações.

Por sua vez, o algodão agroecológico vem sendo produzido em assentamentos rurais nos estados do Ceará, Pernambuco, Rio Grande do Norte e Paraíba, incentivado por associações locais e pelo próprio Ministério do Desenvolvimento Agrário $(\mathrm{MDA})^{7}$ (LIMA e SOUZA, 2006; BOSSLE et al., 2012). O cultivo do algodão agroecológico em consórcio com outras culturas, além de reduzir o risco associado à perda de safra e agregar mais valor à produção, poderia gerar benefícios como a redução dos custos produtivos e vantagens agronômicas vinculadas ao controle de pragas, uma vez que a diversidade de culturas presentes no consórcio dificulta o aumento da densidade dos insetos (SILVA, 2009). Segundo Lima e Souza (2006), o preço de venda do algodão agroecológico pode ser entre $25 \%$ (para o caroço) e $100 \%$ (para a pluma) maior do que o valor pago pelo algodão convencional. Esse diferencial dependeria, entretanto, do grau de articulação dos produtores com mercados que valorizem a mão de obra

7. Ação do Projeto Dom Helder Câmara (PDHC), do MDA, criada com o objetivo de fortalecer a reforma agrária e a agricultura no semiárido nordestino. 
familiar e modelos de produção ambientalmente sustentáveis, como as redes de comércio justo.

Além da busca por diferenciais de preços com a venda da pluma colorida ou agroecológica, outra estratégia que vem sendo adotada por pequenos produtores de algodão envolve a busca por ganhos de produtividade a partir da adoção de tecnologias ou práticas comuns aos grandes produtores, como sementes GMs, manejo integrado de pragas, subsolagem e plantio adensado (RAMOS, 2014). Um estudo de caso na região de Catuti, no norte de Minas Gerais, identificou na cooperativa local, a Coopercat, o principal responsável por romper o bloqueio ao uso de cultivares GMs por pequenos agricultores, estimulado principalmente por organizações públicas (RAMOS, 2014; SCHIFFER, 2007).

Segundo Silveira et al. (2013), a difusão de sementes GM na pequena agricultura ainda está limitada a um número que não ultrapassaria 3.000 produtores nas regiões do sudeste baiano e do norte de Minas Gerais. Estudos internacionais destacam, todavia, os potenciais benefícios de cultivares $\mathrm{GM}$ entre pequenos agricultores. $\mathrm{O}$ uso de sementes resistentes a insetos pragas $(\mathrm{Bt})$ contribuiria para reduzir o risco de infestações e aumentar a produtividade, além de reduzir o número de aplicações de defensivos tóxicos ao meio ambiente (ver, por exemplo, HUANG et al., 2002; QAIM et al., 2006). As sementes tolerantes a herbicidas (RR) facilitariam o manejo de pestes, atributo fundamental em culturas intensivas em trabalho, e reduziriam a aplicação de alguns tipos de herbicidas mais tóxicos ao ambiente (QAIM e TRAXLER, 2005).

Ainda assim, existem controvérsias, pois os impactos sobre os lucros dos produtores ainda são questionáveis, uma vez que a parte principal dos benefícios da tecnologia GM poderia ser apropriada pelas empresas desenvolvedoras das sementes sob a forma de royalties. Para alguns autores, os benefícios seriam maiores para os grandes produtores, uma vez que o sucesso dependeria não somente da adoção do tipo de semente, mas também de um amplo conjunto de técnicas de manejo, muitas vezes inacessíveis aos pequenos produtores (ARZA et al., 2012).
Por um lado, o cultivo de sistemas agroecológicos possibilita a inserção de pequenos produtores em redes de comercialização que privilegiam conceitos como consumo responsável ou sustentável. Por outro lado, exclui a possibilidade de uso de sementes GM na cotonicultura, como ocorre no norte da Argentina e na região Nordeste do Brasil (ARZA e ZWANENBERG, 2013). Haeberlin et al. (2012) apontam ainda certa inadequação do uso de cultivares GM por agricultores de algodão na região de Córdoba, na Colômbia, em função do maior custo das sementes e dos custos de adaptação à nova tecnologia. Enfatizam que a variabilidade existente nas condições de ocorrência de pragas cria situações em que cultivares convencionais são mais rentáveis que os cultivares GMs.

De maneira geral, pode-se afirmar que a adoção de sementes ou de novos sistemas de produção depende, de um lado, das condições de oferta e demanda de sementes do tipo desejado, nas regiões produtoras. De outro lado, depende também da própria disposição dos produtores a aceitarem mudanças no desenvolvimento de suas culturas. Decisões essas que se baseiam tanto em avaliações objetivas sobre os custos e benefícios econômicos, como em percepções subjetivas sobre, por exemplo, confiança e aversão ao risco (MAIA e SILVEIRA, 2013).

\subsection{Adoção e difusão de tecnologias na agricultura}

A adoção de uma determinada tecnologia é uma decisão do indivíduo, do agente envolvido, e a difusão trata da caracterização do caminho percorrido pela inovação ao longo de um determinado grupo de agentes econômicos ou sociais. Há uma forte associação entre as decisões individuais e o processo coletivo, que se dá no âmbito do mercado. Na agricultura, Souza Filho et al. (2011) apontam para vários elementos que condicionam os processos de adoção e difusão de inovações: a) as condições socioeconômicas e as características dos produtores, como grau de organização, aversão ao risco, experiência do produtor na agricultura; b) características da produção 
(dos sistemas produtivos) e das propriedades rurais (incluindo a heterogeneidade espacial); c) características da tecnologia (principalmente sua divisibilidade e relação com o volume de capital requerido para inovar); d) fatores sistêmicos (assistência técnica e mecanismos de difusão da informação, políticas específicas para incentivar adoção, direitos de propriedade associados à recepção de benefícios sociais).

Fatores estruturais e institucionais são determinantes fundamentais da caracterização dos processos coletivos. Há setores da economia em que existe o interesse social para que certas inovações ocorram. O setor agrícola é o caso mais evidente em que a criação de um sistema de inovações é fruto deliberado da evolução de políticas (HAYAMI e RUTTAN, 1971; WRIGHT, 2013). A ideia é que o setor é chave para o bem-estar da população, desde o foco na segurança alimentar até no sentido Rawlsiano (privilegiar os que estão em piores condições). Portanto, políticas buscam combinar as características da tecnologia com agricultores-alvo e com fatores sistêmicos, gerando um enfoque abrangente para o tratamento dos processos de adoção e difusão (SPIELMANN et al., 2012).

Em trabalho seminal, Rogers (1971) apresenta a ideia de que existe um padrão geral no processo de difusão de inovações e que este se relaciona com certas condições de adoção. $\mathrm{O}$ autor define um padrão geral de difusão das tecnologias, na forma de $\mathrm{S}$ (derivado de uma curva em forma de sino), determinado por duas variáveis básicas: o lucro do inovador, o prêmio ao pioneirismo que incentiva a adoção da inovação tecnológica - e o custo de adoção - que coloca um limiar à inovação e a relaciona com o custo de aprendizagem, de adaptação e à capacidade de absorção do conhecimento (VIEIRA FILHO e SILVEIRA, 2011). Tem-se uma tipologia que separa pioneiros, seguidores e retardatários, um modelo descritivo importante, mas com pouca capacidade de gerar previsões sobre o futuro da tecnologia. Diederen et al. (2003) demonstraram que o modelo de difusão baseado na combinação do modelo de contato e de difusor central tem grande poder explicativo dos processos ocorridos entre agricultores na Holanda, em uma agricultura com baixo nível de heterogeneidade estrutural.

As inovações biológicas estão no centro do processo mais recente de integração das tecnologias voltadas para a transformação da agricultura, quando esta efetivamente se integra ao processo de desenvolvimento industrial e econômico de um país, o que é típico de países desenvolvidos (TIMMER, 1998). A aplicação de modelos tradicionais sobre os processos de difusão tecnológica, o de base epidemiológica (ou de contato), o modelo do difusor central e também a combinação de ambos (GEROSKY, 2000) resultaram em trabalhos seminais, como o de Grilliches (1957), que localiza no tempo e no espaço a utilização de sementes híbridas de milho nos EUA, no período de 1930 a 1950. O trabalho identifica de forma pioneira o padrão na forma de $S$ da adoção dessa nova tecnologia a partir do centro difusor, que foram as instituições de pesquisa públicas e privadas no estado de Ohio nos EUA. Vieira Filho (2014) conclui que o modelo de função logística, que contrapõe o ganho do inovador ao custo de adoção ao longo de um período de difusão de uma determinada tecnologia é o que melhor se ajusta ao caso da difusão de sementes transgênicas no Brasil.

Os estudos de difusão e condições de adoção de inovações tecnológicas na agricultura tornam-se ainda mais importantes quando existe forte heterogeneidade estrutural, como no caso brasileiro (VIEIRA FILHO, 2014). É precisamente o caso abordado neste trabalho, uma vez que a adoção de sementes depende do sistema produtivo que a elas melhor se ajusta, com um nível de complexidade superior ao dos problemas tratados nos estudos clássicos, como o de Grilliches (1957).

\subsection{A adoção de sementes e sistemas de produção na agricultura}

A adoção de novos tipos de sementes e de sistemas de produção na agricultura pode ser determinada por fatores diversos. Há fatores exógenos à produção, como aspectos institucionais locais, 
associados, por exemplo, à disponibilidade de sementes e à orientação técnica dos órgãos competentes; a estrutura dos mercados de crédito e produtos e a disposição dos consumidores a pagar pelos novos produtos. Fatores endógenos também são importantes, como características dos sistemas atuais de produção, características socioeconômicas do produtor, como escolaridade e experiência profissional, e as próprias preferências individuais, que refletiriam, por exemplo, a disposição a adotar um novo sistema de produção.

A literatura internacional destaca que a assistência técnica e o acesso ao crédito podem aumentar as chances de adoção de variedades melhoradas de sementes por pequenos produtores em países em desenvolvimento (FELEKE e ZEGEYE, 2005; ABEBE et al., 2013). De certa maneira, o entendimento dos fatores que condicionam os processos de adoção e difusão tecnológica foi central para a chamada Revolução Verde, apoiada nas sementes híbridas de alto rendimento. Modificações nas características aportadas pelas sementes implicam redefinir o padrão tecnológico, principalmente a escolha de insumos e suas quantidades. Sementes melhoradas se tornam a chave de estratégias que buscam apropriar a intensificação no uso da terra por pequenos agricultores avessos ao risco, em função de seu baixo custo de adoção e de sua divisibilidade (BARRET, 1993). Por outro lado, a objeção de vizinhos em relação a produtos GM pode afetar negativamente a escolha dos produtores por suas sementes (BREUSTEDT et al., 2007). No Brasil, essa objeção pode estar relacionada a atitudes dos produtores vinculadas à percepção de riscos, aceitação de novas tecnologias, ou mesmo a questões ambientais relacionadas ao cultivo de GMs (MAIA e SIVEIRA, 2013).

No que se refere às características dos produtores, a escolaridade, que está associada ao acesso à informação e ao conhecimento científico e tecnológico, afetaria positivamente a adoção de sementes melhoradas e GMs (ABEBE et al., 2013; BREUSTEDT et al., 2007; FELEKE e ZEGEYE, 2005; FERNANDO-CORNEJO et al., 2001; HUBBEL et al., 2000; KOLADY e LESSER, 2006). A idade e a experiência profissional usualmente também influenciam as preferências declaradas do produtor. Se por um lado a idade do produtor pesa negativamente na propensão a adotar sementes melhoradas ou transgênicas, o tempo de experiência com agricultura influencia positivamente na adoção (ALEXANDER e VAN MELLOR, 2005; FELEKE e ZEGEYE, 2005; SHIYANI et al., 2012).

Uma vez que a adoção de novos sistemas de cultivo pode exigir mudanças nas técnicas e nos retornos marginais da produção, é esperado que sua adoção esteja condicionada a uma série de fatores econômicos, como os preços pagos pelos produtos, custos marginais e área de produção e outros insumos de produção. Por exemplo, estudos sugerem que a adoção de novos sistemas de produção GM entre pequenos produtores esteja condicionada positivamente ao número de membros familiares, número de empregados, ou mesmo animais na propriedade (ALEXANDER e VAN MELLOR, 2005; FELEKE e ZEGEYE, 2005; FERNANDO-CORNEJO et al., 2001; KOLADY e LESSER, 2006).

Como já foi apontado, o processo de difusão e adoção de sementes de algodão e seus correspondentes sistemas produtivos na pequena agricultura do Brasil é datado e corresponde a um processo de retomada, motivado pelo interesse dos agricultores em terem cultivos que sejam além da produção para o autoconsumo. A difusão está relacionada a iniciativas organizadas, com forte participação de instituições públicas, nos casos de cultivares não transgênicos, e da iniciativa privada no caso dos cultivares transgêni$\cos (\mathrm{GM})$.

\section{Metodologia}

\subsection{Fonte de dados}

Os dados utilizados nesse trabalho foram obtidos de entrevistas aplicadas em 2011 a pequenos produtores de algodão em 33 municípios produtores dos estados da Bahia, Paraíba, Rio 
Grande do Norte, Minas Gerais e Goiás. Primeiro, foi selecionada uma amostra piloto de 40 produtores na Paraíba para validação das respostas. Como todas as questões apresentaram respostas válidas e consistentes, o mesmo questionário foi aplicado a outros 157 produtores, totalizando uma amostra de 197 questionários. Os produtores foram selecionados segundo indicações de especialistas da Embrapa, técnicos e representantes de cooperativas regionais de produtores de algodão. A seleção amostral não probabilística se justifica por não haver informações apuradas sobre o universo de pequenos produtores para cada tipo de algodão cultivado, sobretudo de sua distribuição no território. Apesar de não se ter a pretensão de extrapolar os resultados desta pesquisa para o universo de pequenos produtores de algodão no Brasil, considera-se, a partir da opinião de especialistas da Embrapa, a amostra representativa de uma ampla diversidade de pequenos produtores de algodão no País.

Os produtores envolvidos no estudo possuíam propriedades com tamanho inferior a 50 hectares e cultivavam cinco tipos de algodão: branco convencional, colorido, agroecológico, transgênico resistente a inseto $(B t)$ e transgênico tolerante a herbicida $(R R)$. O questionário continha informações sobre: preferências dos produtores em relação às espécies cultivadas (preferências reveladas); preferências por espécies que estariam dispostos a adotar (preferências declaradas); características socioeconômicas do produtor e características do sistema de produção. O tipo de algodão cultivado em 2011 representou a preferência revelada do produtor em relação à semente ou ao sistema de produção. Por sua vez, as preferências declaradas foram obtidas solicitando ao produtor que ordenasse múltiplas alternativas de cultivo de algodão. Uma breve descrição das características de cada sistema produtivo era previamente apresentada aos produtores para balizar suas avaliações. Uma descrição mais detalhada das questões é apresentada nos próximos tópicos, durante a apresentação dos métodos de pesquisa.

Foram ainda realizadas entrevistas com agentes locais (representantes de cooperativas, secretários municipais de agricultura, extensionistas e pesquisadores) para um acompanhamento qualitativo da pesquisa. Um questionário semiestruturado foi utilizado para discutir aspectos associados ao histórico e características da cotonicultura na região, suporte das instituições locais, custos e valores de venda da produção, entre outros, com os agentes. As entrevistas foram utilizadas fundamentalmente para contextualizar e validar os resultados das entrevistas com os produtores.

\subsection{Preferências Reveladas: Análise de Correspondência Múltipla (ACM)}

A relação entre as preferências reveladas dos produtores por cada um dos cinco sistemas de produção (branco convencional, colorido, agroecológico, Bt e RR) e as características socioeconômicas do produtor e do sistema de produção pôde ser melhor compreendida com o emprego da técnica de ACM (GREENACRE, 1984). A ACM é uma técnica de análise exploratória multivariada que reduz a dimensionalidade das associações, permitindo, em seguida, a representação espacial simultânea e resumida de inúmeras características qualitativas de interesse. A partir de uma tabela de contingência com múltiplas combinações de categorias qualitativas, a ACM elimina o uso de informações redundantes e determina o número de dimensões pertinentes a serem consideradas para se compreender a estrutura de associações entre as categorias de análise. A ACM se baseia na técnica de componentes principais para simplificar a estrutura dos dados, explicando, em um número reduzido de dimensões, a maior parcela de informação presente nos dados (CUADRAS, 1981). Após identificar as principais dimensões (componentes) representativas da variação dos dados, a análise de correspondência facilita a compreensão da estrutura de associações existentes entre as categorias.

Baseando-se em princípios algébricos da decomposição em valores singulares, segundo os quais a estrutura básica de uma matriz pode ser decomposta em valores e vetores básicos, 
a técnica decompõe a estrutura das distâncias entre as categorias de interesse (distâncias $\chi^{2}$ ) em (i) autovalores que representam as contribuições parciais de cada dimensão na variabilidade total, e (ii) autovetores que representam planos de projeção geométrica dos perfis linhas das subpopulações (GREENACRE e HASTIE, 1987). A inércia total corresponde ao grau de distanciamento médio das múltiplas combinações de frequências em relação ao comportamento médio da população. Os $K$ autovalores $\lambda_{1}, \ldots, \lambda_{K}$ obtidos pela decomposição da inércia total são chamados de inércias principais e correspondem às contribuições parciais das respectivas dimensões.

A dispersão geométrica das categorias no espaço definido pelas dimensões da análise de correspondência mostra a natureza das associações entre as variáveis qualitativas do problema. Grupos de categorias próximas revelam similaridades nas associações, enquanto grupos distantes significam repulsão entre as categorias (HOFFMANN e FRANKE, 1986). Categorias próximas à origem de uma dimensão (centróide) significam baixas contribuições para a respectiva inércia principal, ou seja, suas frequências pouco se distinguem em relação à estrutura representada pela dimensão.

\subsection{Preferências Declaradas: Análise Conjunta (AC)}

As preferências declaradas dos produtores em relação ao seu sistema de produção foram avaliadas por meio da Análise Conjunta (LOUVIERE et al., 2000). Diversos sistemas de produção foram apresentados como alternativas aos produtores, solicitando que esses ordenassem suas escolhas segundo suas preferências. Para cada alternativa de sistema escolhido pelo produtor, a AC estimou um valor para sua utilidade ordinal. O objetivo é calcular o valor da utilidade de tal maneira que as utilidades de cada sistema sejam tanto quanto possível semelhantes às ordenações de classificação original.

Diferentes formatos de estudos de escolha podem ser aplicados, por exemplo: escolha contingente; classificação contingente e ordenação contingente (GONZALES et al., 2004). Escolha contingente pede ao entrevistado para relatar uma escolha em um conjunto de alternativas. Este formato fornece dados fracamente ordenados, uma vez que apenas uma resposta não permite uma ordenação completa das preferências. No formato de classificação contingente, os entrevistados classificam cada conjunto de alternativas em uma escala de classificação das categorias. Embora os dados neste formato sejam mais bem ordenados do que na escolha contingente, $\mathrm{o}$ modelo faz suposições muito fortes sobre as capacidades cognitivas da pessoa (LOUVIERE et al., 2000). Nesse trabalho foi utilizada a ordenação contingente, que fornece uma ordem de preferência completa, embora sem nenhuma informação sobre as diferenças em relação ao grau de preferência.

As preferências dos produtores para cada tipo de sistema foram modeladas por um rank-ordered logit model, ou modelo lógite de classificação ordenada (Allison e Christakis, 1994). Seja $U_{\mathrm{ij}}$ a utilidade atribuída à $j$-th alternativa pelo produtor $i$, pode-se supor que $U_{\mathrm{ij}}$ seja uma variável aleatória com um componente sistemático (determinístico) $\eta_{\mathrm{ij}}$ e um erro não observável $\varepsilon_{\mathrm{ij}}$ :

$$
U_{i j}=\eta_{i j}+\varepsilon_{i j}
$$

Embora a utilidade $U$ não seja mensurada no experimento, é possível estimar a probabilidade de um produtor escolher a alternativa $j$ em comparação à alternativa de referência $k$. O produtor apenas optará pela alternativa $j$ em comparação à $k$ caso sua utilidade $U_{\mathrm{ij}}$ seja maior que $U_{\mathrm{ik}}$. Assim, se $Y_{\mathrm{i}}$ representa a escolha feita pelo produtor $i$, a probabilidade de este escolher a alternativa $j$ será dada por:

$$
\operatorname{Pr}\left(Y_{i}=j\right)=\operatorname{Pr}\left(U_{i j}>U_{i k}\right)
$$

A partir de alguns pressupostos sobre a distribuição do termo de erro $\varepsilon_{\mathrm{ij},}$ pode-se modelar esta probabilidade por:

$$
\operatorname{Pr}\left(Y_{i}=j\right)=\frac{e^{\eta_{j j}}}{e^{\eta_{1 / k}}}
$$


Assim, o componente sistemático $\eta_{\mathrm{ij}}$ pode ser expresso como uma função das características dos produtores $\left(\mathrm{x}_{\mathrm{i}}\right)$ :

$$
\eta_{i j}=\mathrm{x}_{i} \beta_{j}
$$

Em que os coeficientes no vetor $\beta_{\mathrm{j}}$ expressam como a aceitação da alternativa $j$ é afetada pelas características do produtor. A interpretação desses efeitos marginais se dá em relação à categoria de referência $k$. Expressam quantas vezes o log das chances de escolha da alternativa $j$ é maior que o log das chances de escolha da alternativa de referência $k$. Para obter a razão direta entre as chances de escolha das duas categorias (odds ratio), basta calcular $e^{\beta}$. Como as características afetam diferentemente a escolha por cada alternativa $j$, cada variável explanatória terá coeficientes distintos entre as alternativas. Neste trabalho, as estimativas de $\beta$ foram obtidas pelo procedimento PHREG do pacote estatístico SAS.

Os dados para as escolhas dos produtores foram obtidos a partir de questionamentos sobre os sistemas que os produtores estariam mais dispostos a adotar. Após uma breve descrição de cada tipo de produção, a questão que se fazia ao produtor era: "Gostaria que o senhor(a) ordenasse as alternativas a seguir de acordo com suas preferências. Coloque em primeiro lugar aquele tipo de semente que o senhor(a) mais desejaria cultivar, em segundo o próximo tipo mais desejado e assim sucessivamente, até o quarto e último tipo, que o senhor(a) menos desejaria cultivar". Solicitava-se, então, que o produtor ordenasse um conjunto de alternativas, cada uma descrevendo características diferentes da produção de algodão. Para cada entrevistado, foram apresentadas aleatoriamente quatro alternativas de um conjunto de sete diferentes tipos de produção: Bt Pirata (sem pagamento de royalty), Bt certificado (com pagamento de royalty), RR Pirata, RR certificado, Agroecológico, Colorido e Branco Convencional. Um número maior de alternativas poderia dificultar as escolhas dos produtores e gerar um elevado número de respostas nulas. Não foram consideradas diferenças entre os preços pagos pelas sementes por dois motivos principais: (i) não havia diferenças expressivas entre os preços médios das sementes no País; (ii) os pequenos produtores usualmente não pagam pelas sementes, que costumam ser doadas por cooperativas, prefeituras e outras instituições locais de apoio à agricultura. Apenas a distinção das sementes transgênicas foi realizada, considerando os seguintes atributos: certificadas, com pagamento médio de royalties de $\mathrm{R} \$ 55,00$ por hectare; e piratas, sem pagamento de royalties e sem garantia de procedência.

A alternativa adotada como referência de análise (alternativa $k$ ) no modelo lógite de classificação ordenada foi o branco convencional. Assim, coeficientes positivos significam uma propensão maior a adotar a alternativa $j$ em comparação ao branco convencional. Após tratamento dos dados e análises preliminares, foram selecionadas as seguintes variáveis explanatórias como principais determinantes das escolhas dos produtores:

- Três variáveis binárias para discriminar quatro tipos de produtores: produtor de algodão Bt ou RR (Produtor GM); algodão Agroecológico (Agroecológico); colorido (Colorido) e branco convencional (referência de análise). As categorias de produtores Bt e RR foram agregadas na categoria Produtor GM para dar mais significância à análise, uma vez que suas escolhas eram semelhantes;

- Uma variável contínua para representar a área da propriedade em hectares (Área).

\section{Resultados}

\subsection{Características dos produtores}

As características socioeconômicas dos produtores entrevistados e as características de seus sistemas de produção são apresentadas na Tabela 1 . Dada a dificuldade para encontrar pequenos produtores que ainda cultivavam o algodão branco convencional no Brasil, a amostra deste grupo limitou-se a 27 produtores (15\% da amostra). A maior parte dos produtores selecionados cultivava algodão agroecológico (71 produtores ou $40 \%$ da 
212 A adoção de Sistemas Produtivos entre Grupos de Pequenos Produtores de Algodão no Brasil

Tabela 1. Descrição das variáveis do questionário e frequências observadas na amostra

\begin{tabular}{|c|c|c|c|c|}
\hline Variável & Descrição & Código & Categoria & $\%$ \\
\hline \multirow{5}{*}{ Tipo } & \multirow{5}{*}{ Tipo de semente } & 1 & $\mathrm{Bt}$ & 20,6 \\
\hline & & 2 & $\mathrm{RR}$ & 11,4 \\
\hline & & 3 & Orgânico & 40,6 \\
\hline & & 4 & Branco & 15,4 \\
\hline & & 5 & Colorido & 12,0 \\
\hline \multirow{5}{*}{ UF } & \multirow{5}{*}{ Unidade da Federação } & $\mathrm{BA}$ & Bahia & 14,9 \\
\hline & & PB & Paraíba & 33,7 \\
\hline & & $\mathrm{RN}$ & Rio Grande do Norte & 18,3 \\
\hline & & MG & Minas Gerais & 18,3 \\
\hline & & $\mathrm{GO}$ & Goiás & 14,9 \\
\hline \multirow{4}{*}{ Esc } & \multirow{4}{*}{ Maior grau de escolaridade } & 0 & $<1^{\circ}$ grau & 16,6 \\
\hline & & 1 & $1^{\circ}$ grau & 65,1 \\
\hline & & 2 & $2^{\circ}$ grau & 14,3 \\
\hline & & 3 & $3^{\circ}$ grau & 4,0 \\
\hline \multirow{3}{*}{ Anos } & \multirow{3}{*}{ Anos de experiência com atividade rural } & 1 & Até 15 & 13,7 \\
\hline & & 2 & 15 a 30 & 26,3 \\
\hline & & 3 & mais de 30 & 60,0 \\
\hline \multirow{2}{*}{ NRem } & \multirow{2}{*}{ Ocupou morador do domicílio não remunerado? } & 0 & Não & 6,9 \\
\hline & & 1 & Sim & 93,1 \\
\hline \multirow{2}{*}{ Temp } & \multirow{2}{*}{ Ocupou trabalhador remunerado temporário? } & 0 & Não & 30,3 \\
\hline & & 1 & Sim & 69,7 \\
\hline \multirow[t]{2}{*}{ Perm } & \multirow{2}{*}{ Ocupou trabalhador remunerado permanente? } & 0 & Não & 90,3 \\
\hline & & 1 & Sim & 9,7 \\
\hline \multirow{2}{*}{ Cred } & \multirow[t]{2}{*}{ Teve acesso a crédito? } & 0 & Não & 65,7 \\
\hline & & 1 & Sim & 34,3 \\
\hline \multirow{4}{*}{ Area } & \multirow{4}{*}{ Área cultivada } & 1 & Até 1 ha & 36,0 \\
\hline & & 2 & 1 a 2 ha & 21,1 \\
\hline & & 3 & 2 a 5 ha & 18,3 \\
\hline & & 4 & mais 5 ha & 24,6 \\
\hline \multirow{6}{*}{ Motivo } & \multirow{6}{*}{ Por que escolheu cultivar esse tipo de algodão? } & 1 & Preço & 6,3 \\
\hline & & 3 & Produtividade & 20,0 \\
\hline & & 4 & Menos agrotóxico & 11,4 \\
\hline & & 5 & Incentivo & 25,7 \\
\hline & & 6 & Disponibilidade & 18,3 \\
\hline & & 8 & Outros & 18,3 \\
\hline & & 0 & Não & 48,0 \\
\hline Irator & Possui trator? & 1 & Sim & 52,0 \\
\hline Mecan & Possui colhedeira ou plantadeira? & 0 & Não & 83,4 \\
\hline viecan & Possur comedeira ou prantaderra? & 1 & Sim & 16,6 \\
\hline & & 0 & Não & 86,3 \\
\hline Auto & Possui caminnao ou caminhonete? & 1 & Sim & 13,7 \\
\hline & & 0 & Não & 40,6 \\
\hline Bicudo & Ocorre bicudo? & 1 & Sim & 59,4 \\
\hline Rosada & Ocorre lagarta rosada? & 0 & Não & 69,1 \\
\hline Kosada & Ucorre lagarta rosada? & 1 & Sim & 30,9 \\
\hline & & 0 & Não & 71,4 \\
\hline Maca & Ocorre lagarta da maçâ? & 1 & Sim & 28,6 \\
\hline Mosca & Ocorre mosca hranca? & 0 & Não & 72,6 \\
\hline Mosca & Ucorre mosca branca! & 1 & Sim & 27,4 \\
\hline Praga & Ocorre outro tine de praga? & 0 & Não & 41,1 \\
\hline Praga & Ucorre outro tipo de praga? & 1 & Sim & 58,9 \\
\hline & & 0 & Não & 12,6 \\
\hline Erva & Ucorre erva daninha? & 1 & Sim & 87,4 \\
\hline
\end{tabular}

Fonte: Dados de pesquisa. 
amostra) e algodão Bt (36 produtores ou $20 \%$ da amostra). A amostra baseou-se, ainda, em pequenos produtores com área inferior a 2 hectares $(57 \%$ da amostra), embora os produtores com 5 ha ou mais de área cultivada também estivessem razoavelmente representados (25\%).

Os resultados também destacam baixo grau de escolaridade e elevada experiência dos produtores da amostra com a atividade agrícola. Apenas $18 \%$ dos produtores cursaram o ensino médio ou superior, e $60 \%$ dos produtores apresentavam mais de 30 anos de experiência com a atividade agrícola. É elevada a participação de moradores no domicílio em auxílio não remunerado à atividade agrícola $(93 \%)$, característica da agricultura familiar no País. A mão de obra assalariada é predominantemente temporária, sobretudo para auxiliar a colheita do algodão. Apenas $6 \%$ dos produtores mantinham trabalhador permanente na atividade.

Foram frequentes as reclamações dos produtores sobre a falta de incentivo das instituições públicas e privadas para atividades nas áreas mais desfavorecidas. Entre as principais queixas estavam: a falta de incentivos das instituições públicas na orientação dos produtores sobre as técnicas corretas de manejo; financiamento da produção e garantia de preço mínimo ao algodão. A dificuldade para concessão e pagamento de crédito agrícola chamou a atenção nas entrevistas. Apenas 34\% dos produtores entrevistados haviam adquirido crédito agrícola na safra corrente. Uma grande dificuldade seria o expressivo descompasso entre a burocracia e a demora na concessão do crédito. Muitos daqueles que adquiriam financiamento acabavam se tornando inadimplentes pela incapacidade de pagamento. É o que também relata Guanziroli (2007) em estudo que analisa a eficiência e eficácia do Programa de Fortalecimento da Agricultura Familiar (Pronaf) no Brasil.

Há forte influência de instituições locais na escolha do tipo de cultura de algodão pelo pequeno produtor. Por muitos produtores não pagarem diretamente pela semente, o motivo da escolha do tipo de semente acaba sendo determi- nado, sobretudo, pela disponibilidade de sementes nas cooperativas ou prefeituras (18\%), ou alguma política de incentivo ou estímulo público à produção $(26 \%)$. Poucos produtores decidiam pelo tipo de semente em função do preço de compra do insumo ou preço de venda do algodão (6\%), mesmo porque este último é caracterizado por alta volatilidade.

Outra característica marcante era a baixa tecnificação dos pequenos produtores. Menos da metade utilizava trator no cultivo de algodão (48\%); muitos desses em sistema de cooperativa. Apenas $17 \%$ mecanizavam a plantação ou a colheita e $14 \%$ possuíam acesso a caminhão ou caminhonete. Usualmente, a colheita era realizada manualmente em sistema de cooperativa pelos produtores de uma comunidade e o transporte do produto ficava sob a responsabilidade da cooperativa, prefeitura ou atravessador.

Entre as pragas que acometem a plantação de algodão, o bicudo continua sendo a mais frequente (ocorria em $60 \%$ das propriedades entrevistadas). Esta praga teria ainda contribuído para o derradeiro declínio da produção de algodão no Nordeste em meados dos anos 1980 (BUAINAIN e BATALHA, 2007), produção esta que voltou a ganhar fôlego no final dos anos 2000 na região. Outras pragas mais frequentes são a lagarta rosada (31\% das propriedades), a mosca branca $(27 \%$ ) e a lagarta da maçã (29\%).

\subsection{Padrões de associação às preferências reveladas}

Após uma análise univariada preliminar das características dos produtores e dos sistemas de produção, foram identificados os principais padrões de relacionamentos entre as variáveis de interesse pela ACM. Esta técnica foi aplicada para reduzir a dimensão das múltiplas combinações das categorias de análise. Seriam necessárias 33 dimensões para representar a variabilidade total (inércia total) dessas categorias, sendo que as três principais dimensões representavam, conjuntamente, 33\% da inércia total. Este número de dimensões foi considerado suficiente pelo fato de 
dimensões adicionais contribuírem muito marginalmente para explicar a variabilidade total.

A contribuição de cada categoria para explicar a inércia das três dimensões (inércias parciais) forneceu argumentos para a interpretação dos resultados da $\mathrm{ACM}$, como será descrito a seguir.

- Dimensão 1: tamanho da propriedade, mecanização e algodão orgânico (15,6\% da inércia total) - Dimensão com maior contribuição sobre a variabilidade total das categorias. É fortemente influenciada pelo grau de mecanização e pelo tamanho da propriedade. No extremo positivo, as categorias que mais contribuem para a inércia desta dimensão são: área com mais de 5 ha $(9 \%)$, possui colhedeira ou plantadeira (7\%), possui caminhão ou caminhonete (7\%). No extremo negativo: área de até 1 ha (4\%), ausência de ocorrência do bicudo (5\%) e plantação de algodão orgânico (5\%).

- Dimensão 2 - algodão branco convencional e Bt (9,3\% da inércia total) - Dimensão fortemente influenciada pelo cultivo de algodão Bt de um lado e, de outro, pelo cultivo de algodão branco convencional. As categorias que mais contribuem para a inércia desta dimensão, no extremo negativo, são: produtor do estado de Minas Gerais $(16 \%)$, com cultivo de algodão $\mathrm{Bt}$ (13\%), área entre 2 e 5 ha (8\%), ocorrência da lagarta rosada (5\%) e escolha de semente motivada pelo baixo uso de defensivos $(4 \%)$. No outro extremo, as categorias mais influentes são: novamente, área de até 1 ha (5\%), contratação de empregado permanente (5\%) e cultivo do algodão branco convencional (4\%).

- Dimensão 3 - acesso ao crédito e algodão RR (8,1\% da inércia total) - É fortemente influenciada pelo cultivo de algodão RR no estado da Bahia de um lado e, de outro, pelo acesso ao crédito no estado de Goiás. As categorias que mais contribuem para a inércia desta dimensão, no extremo negativo, são: produtor do estado da Bahia (19\%), com cultivo de algodão RR (15\%), ocorrência de mosca branca (6\%), a inexistência de acesso a trator na propriedade (4\%) e escolha motivada pela disponibilidade de semente na região (4\%). No extremo positivo, as categorias mais influentes são: produtor do estado de Goiás (8\%) com acesso ao crédito $(6 \%)$.

A dispersão das categorias de análise nas 3 principais dimensões da ACM permitiu analisar os padrões de associação entre as características dos pequenos produtores de algodão (Figura 1). Lembrando que características que apresentam localizações próximas no espaço euclidiano

Figura 1. Distribuição das categorias de análise nas três principais dimensões da ACM

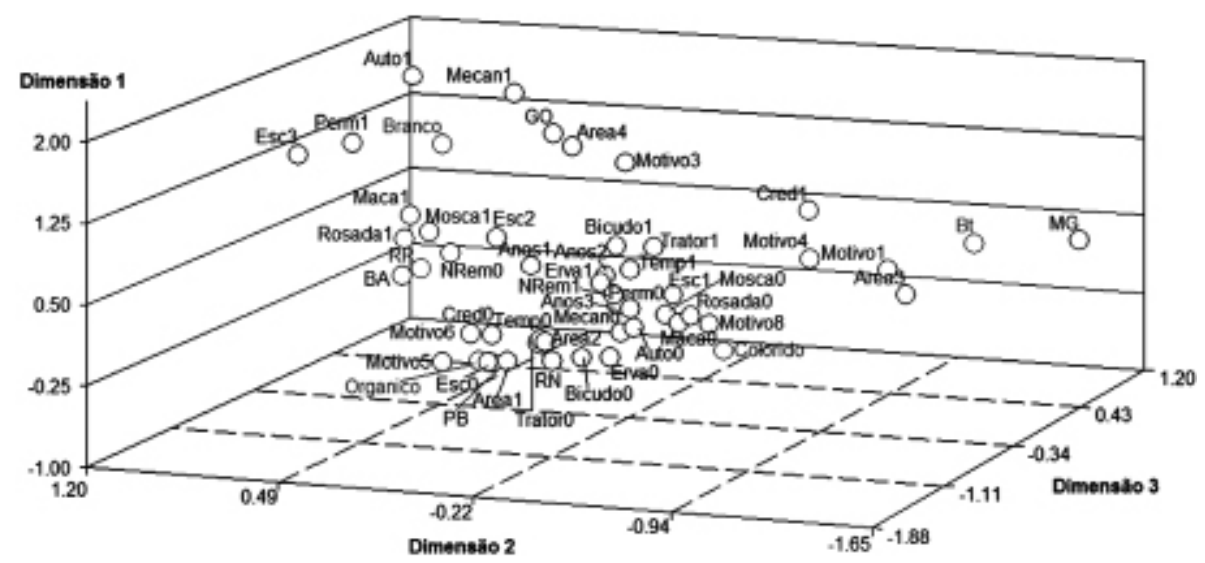

Fonte: Dados de pesquisa. 
formado pelas dimensões da ACM estão associadas entre si. As distâncias entre essas não podem, entretanto, ser interpretadas como padrões de relação positiva ou negativa das categorias de interesse.

Fortemente influenciado por valores extremos negativos para a dimensão 1 (tamanho da produção, mecanização e algodão agroecológico), observa-se um padrão de associação entre os produtores de algodão agroecológico (categoria Organico no gráfico) à pequena propriedade (Area1 e Area2, até 2 ha), baixíssimo grau de escolaridade ( $E s c 0$, menos que $1^{\text {o }}$ grau), ausência de crédito para a produção (Cred0) e de contratação de mão de obra temporária (Temp0). Dentre os produtores de algodão agroecológico, 96\% possuíam propriedade de até 2 hectares, 21\% participaram, no máximo, no programa de alfabetização de adultos, $92 \%$ não tiveram acesso ao crédito e $44 \%$ não realizavam contratação temporária para a colheita do algodão. A principal justificativa para a escolha deste sistema de produção (62\%) foi o incentivo de instituições locais (cooperativas, prefeitura, agências de pesquisa, entre outras). Estes produtores foram encontrados nos estados da Paraíba e Rio Grande do Norte.

Os produtores de algodão colorido (Colorido) foram encontrados nos estados da Paraíba e Goiás e também se associavam a situações extremas no tamanho da propriedade e mecanização (Dimensão 1). Este tipo de produção estava associado, sobretudo, à ausência de acesso a caminhão ou caminhonete na propriedade $(A u t o 0)$ - o transporte da produção era realizado pela cooperativa ou por intermediário -, trator (Trator0) e de mecanização na plantação ou colheita (Mecan0), à não contratação de mão de obra permanente (Perm0) e ao primeiro grau completo ou incompleto de escolaridade do produtor (Esc1). Não foi registrado nenhum caso de mecanização ou de acesso a trator nas propriedades que cultivavam algodão colorido. Também foi praticamente nulo o registro de ocorrências de pragas na safra atual e de produtores com $2^{\mathrm{o}}$ grau ou mais de escolaridade.
Os produtores de algodão branco convencional (Branco) estão associados a características com valores extremos inferiores para a Dimensão 2 (algodão branco convencional e Bt) e valores extremos superiores para a dimensão 1 (tamanho da propriedade, mecanização e algodão orgânico). Dentre as principais características associadas a esse tipo de produção, destacam-se: o maior grau de escolaridade ( $E s c 3,7 \%$ com $3^{\circ}$ grau de escolaridade completo ou incompleto), contratação de empregados permanentes (Perm1, 26\% contratam empregados permanentes), existência de acesso a caminhonete ou caminhão (Auto1, $52 \%$ das propriedades), mecanização da plantação ou colheita (Mecan1, 56\% das propriedades). Estes produtores foram encontrados, sobretudo, no estado de Goiás e o principal motivo para a escolha deste tipo de produção foi a produtividade $(44 \%)$.

No extremo superior da Dimensão 2 (algodão branco convencional e $\mathrm{Bt}$ ), aparecem os produtores de algodão GM Bt $(B t)$ associados à propriedade de 2 a 5 ha (Area3) e acesso ao crédito (Cred1). Entre esses produtores, 36\% apresentavam área entre 2 e 5 hectares ( $81 \%$ com área superior a 2 hectares) e $69 \%$ tiveram acesso ao crédito para a produção de algodão. Aparecem ainda associados à escolha do algodão Bt pelo menor uso de defensivos (Motivo4) e relação entre preço de compra e venda (Motivo1). Esses produtores foram entrevistados nos estados de Minas Gerais e Bahia.

Finalmente, os produtores de algodão GM RR (RR) apresentaram valores extremos inferiores para a Dimensão 3 (acesso ao crédito e algodão RR) e estavam associados à ausência de emprego de integrante domiciliar não remunerado em auxílio à produção (Nrem0, nenhum registo de mão de obra não remunerada) e à ocorrência de inúmeras pragas na plantação de algodão. Dentre esses produtores, 35\% declararam presença da lagarta rosada, 55\%, da lagarta da maçã e $80 \%$, da mosca branca (Rosada1, Maca1, Mosca1). Estes produtores foram entrevistados nos estados da Bahia e Minas Gerais. 


\subsection{Determinantes das preferências declaradas}

As relações de causa e efeito entre as características dos produtores e a preferências declaradas por sistemas que estariam mais dispostos a adotar foram analisadas pela AC (equação 3). A AC comparou a probabilidade de escolha de cada tipo de sistema em relação à categoria de referência (algodão branco convencional). As estimativas finais obtidas pelo método de máxima verossimilhança são apresentadas na Tabela 2. Todas as variáveis presentes na Tabela 1 foram inicialmente testadas como regressores do modelo lógite de escolha ordinal. Foram, entretanto, mantidos apenas os regressores que se mostraram mais significativos, sem que a exclusão dos demais regressores comprometesse a consistência das estimativas. De maneira geral, o ajuste final mostrou-se significativo, com nível de significância observado para a estatística Likelihood Ratio inferior a 0,1\%.

Tabela 2. Estimativas de máxima verossimilhança para o modelo lógite de classificação ordenada

\begin{tabular}{|c|c|c|c|c|c|}
\hline Parâmetro & Estimativa & $\begin{array}{c}\text { Razão de } \\
\text { Chances }\end{array}$ & Erro Padrão & Qui-quadrado & valor $p$ \\
\hline \multicolumn{6}{|l|}{ Constante } \\
\hline Bt Pirata & $-1,5213$ & 0,2184 & 0,702 & 4,692 & 0,0303 \\
\hline $\mathrm{Bt}$ & $-1,1708$ & 0,3101 & 0,481 & 5,925 & 0,0149 \\
\hline RR Pirata & $-3,2965$ & 0,0370 & 0,948 & 12,089 & 0,0005 \\
\hline RR & $-0,6146$ & 0,5408 & 0,461 & 1,776 & 0,1827 \\
\hline Orgânico & $-0,5657$ & 0,5680 & 0,667 & 0,720 & 0,3963 \\
\hline Colorido & $-1,3721$ & 0,2536 & 0,801 & 2,933 & 0,0868 \\
\hline \multicolumn{6}{|c|}{ Produtor GM } \\
\hline Bt Pirata & 1,4498 & 4,2622 & 0,799 & 3,293 & 0,0696 \\
\hline $\mathrm{Bt}$ & 2,6404 & 14,0190 & 0,605 & 19,060 & $<.0001$ \\
\hline RR Pirata & 4,0744 & 58,8169 & 1,026 & 15,772 & $<.0001$ \\
\hline RR & 2,4792 & 11,9317 & 0,616 & 16,194 & $<.0001$ \\
\hline Orgânico & 0,1875 & 1,2062 & 0,857 & 0,048 & 0,8268 \\
\hline Colorido & 1,1374 & 3,1186 & 0,926 & 1,510 & 0,2192 \\
\hline \multicolumn{6}{|l|}{ Orgânico } \\
\hline Bt Pirata & 0,4701 & 1,6001 & 1,485 & 0,100 & 0,7516 \\
\hline $\mathrm{Bt}$ & 2,2401 & 9,3940 & 1,233 & 3,302 & 0,0692 \\
\hline RR Pirata & 2,0923 & 8,1033 & 1,690 & 1,533 & 0,2157 \\
\hline RR & $-0,3147$ & 0,7300 & 1,211 & 0,068 & 0,795 \\
\hline Orgânico & 3,4533 & 31,6042 & 1,372 & 6,337 & 0,0118 \\
\hline Colorido & 0,9607 & 2,6135 & 1,656 & 0,336 & 0,5619 \\
\hline \multicolumn{6}{|l|}{ Colorido } \\
\hline Bt Pirata & 2,5749 & 13,1300 & 1,608 & 2,564 & 0,1093 \\
\hline $\mathrm{Bt}$ & 1,9702 & 7,1718 & 1,254 & 2,470 & 0,116 \\
\hline RR Pirata & $-10,8133$ & 0,0000 & 851,343 & 0,000 & 0,9899 \\
\hline RR & 1,8962 & 6,6608 & 1,321 & 2,061 & 0,1512 \\
\hline Orgânico & 3,4989 & 33,0781 & 1,535 & 5,195 & 0,0227 \\
\hline Colorido & 4,8394 & 126,3948 & 1,512 & 10,245 & 0,0014 \\
\hline \multicolumn{6}{|l|}{ Área } \\
\hline Bt Pirata & $-0,0002$ & 0,9998 & 0,001 & 0,035 & 0,8525 \\
\hline Bt & 0,0004 & 1,0004 & 0,001 & 0,209 & 0,6475 \\
\hline RR Pirata & $-0,0019$ & 0,9981 & 0,005 & 0,155 & 0,6935 \\
\hline RR & 0,0027 & 1,0027 & 0,002 & 1,302 & 0,2538 \\
\hline Orgânico & $-0,1216$ & 0,8855 & 0,057 & 4,520 & 0,0335 \\
\hline Colorido & $-0,0418$ & 0,9591 & 0,039 & 1,177 & 0,2779 \\
\hline
\end{tabular}

Fonte: Dados da pesquisa. 
As estimativas associadas à cada categoria da variável explanatória tipo de produção (algodão branco convencional - referência, produtor GM, agroecológico e colorido) expressam como as chances de escolha de uma alternativa (Bt Pirata, Bt, RR Pirata, RR, Agroecológico e Colorido) variam em relação à escolha de alternativa de referência (branco convencional) para cada categoria. As estimativas associadas à constante referem-se às preferências dos produtores de algodão branco convencional, referência de análise para a variável explanatória tipo de produção. Seus valores negativos significam que o algodão branco convencional é o tipo preferido entre os produtores de algodão branco. Por exemplo, para os produtores de algodão branco convencional, a chance de escolha de uma semente Bt certificada representa apenas $31 \%$ da chance de escolha de uma semente de algodão branco convencional $\left(e^{-1,1708}=0,3101\right)$. Ou seja, há uma aversão à mudança entre esses produtores. Por sua vez, como as estimativas associadas ao algodão agroecológico e RR (certificado) são insignificantes, não haveria diferenças expressivas entre as escolhas desses tipos de sementes e de algodão branco entre os produtores de algodão branco convencional.

Por sinal, a aversão à mudança se observou em todos os grupos de produtores. Por exemplo, os produtores de algodão GM estão mais propensos a escolher uma semente Bt ou RR, mesmo que esta seja pirata. Para esses produtores, não haveria diferenças significativas entre as escolhas por sistemas agroecológicos, algodão colorido ou algodão branco convencional. Analogamente, os produtores de algodão agroecológico estão mais propensos a continuar com seus sistemas em relação ao branco convencional, assim como os produtores de algodão colorido. Também é importante destacar que, para esses produtores agroecológicos e de algodão colorido, a escolha pelas sementes Bt mostrou-se preferível à do algodão branco convencional, a uma significância máxima de 11,6\%. Para os produtores de algodão agroecológico, a produção de algodão colorido também aparece como alternativa atraente ao cultivo do branco convencional.
Os resultados da AC sugerem ainda que não houve clara preferência revelada em relação à escolha por sementes GM certificadas, com pagamento de royalties, ou piratas. Por exemplo, embora entre os produtores de algodão GM o maior valor de utilidade para as sementes GM tenha sido atribuído à semente RR pirata, o menor valor para essas sementes fora atribuído à semente Bt pirata. Dentre os produtores de algodão colorido, a semente Bt pirata recebeu o maior valor de utilidade dentre as sementes GM. Mas, dentre os produtores de algodão agroecológico, a semente Bt certificada apresentou o maior valor de utilidade entre as sementes GM.

As estimativas associadas à variável explanatória Área expressam como as chances de escolha de uma alternativa (Bt Pirata, Bt, RR Pirata, RR, Agroecológico e Colorido) variam em relação à escolha de alternativa de referência (Branco convencional) à medida que aumenta a área do produtor. Apenas a comparação entre a escolha por algodão orgânico e branco convencional mostrou-se significativa. Seu sinal negativo indica que produtores de áreas menos extensas estariam mais propensos a adotarem o algodão agroecológico em comparação ao algodão branco convencional. O maior preço pago pela pluma e a necessidade de manejo intensivo em mão de obra, decorrente das próprias especificidades do sistema de produção, contribuiriam para as escolhas do sistema agroecológico dentre os pequenos produtores.

\section{Discussão final}

Os resultados deste trabalho destacam, primeiro, o baixo padrão de tecnificação dos pequenos produtores de algodão no Brasil. A taxa de mecanização do plantio e colheita do algodão é muito baixa. Prevalece ainda o cultivo com emprego da mão de obra domiciliar não remunerada ou com contratação de trabalhador temporário no período da colheita. Também são frequentes as reclamações sobre a ausência de assistência das instituições públicas e privadas, sobretudo nas áreas menos favorecidas. Menos de um terço dos 
pequenos produtores entrevistados utiliza crédito na produção de algodão, apesar dos esforços realizados pelo governo para expansão do crédito rural para esse grupo no período.

Cenário análogo foi observado na Argentina, onde, conforme Arza e Zwanenrberg (2013), a retomada do algodão por pequenos agricultores se deu em condições extremamente desfavoráveis, necessitando de suporte institucional, de soluções para gargalos tecnológicos e, principalmente, de formas de acesso a mercados diferenciados. Observou-se, todavia, que no Brasil há uma grande diversidade de iniciativas. Mesmo entre pequenos produtores há importantes heterogeneidades tecnológicas entre os sistemas de produção do algodão, como mostram os padrões de associação às preferências reveladas obtidos pela ACM.

Os resultados demostram que o produtor de algodão agroecológico é aquele com as condições socioeconômicas mais precárias: baixa escolaridade, menor tamanho da propriedade e ausência de crédito na produção. O motivo da escolha deste sistema de produção está muito associado ao incentivo de instituições locais. Essas instituições contribuem para a estruturação do sistema de produção por meio do fornecimento de insumos e de assistência técnica, como é o caso da Embrapa. Sua viabilidade está condicionada, entretanto, à limitação da área de cultivo em razão do uso intensivo da mão de obra familiar. A produção de algodão colorido também se caracteriza pelo baixo nível tecnológico e pelo emprego predominante da mão de obra familiar. O principal motivo de escolha dos produtores por este tipo de cultivo é a disponibilidade de sementes na região, fornecidas usualmente pelas cooperativas e órgãos públicos locais. A área do estabelecimento também se mostrou significativa na determinação da escolha pelo sistema agroecológico. Uma vez que este sistema é intensivo em mão de obra, mostrou-se mais atraente para os produtores com menores áreas de cultivo, sobretudo em um contexto de produção com predomínio da agricultura familiar, em que a contratação de mão de obra temporária ou permanente é muito escassa.
Ainda de acordo com os resultados da análise dos padrões de associação às preferências reveladas, os produtores de algodão branco convencional e transgênico, além de apresentarem grau mais elevado de escolaridade e possuírem propriedades maiores que as dos produtores de algodão orgânico e colorido, atribuem um peso maior à escolha dos fatores que afetam diretamente $\mathrm{o}$ desempenho produtivo. Segundo os resultados da ACM, o principal motivo indicado pelos produtores de algodão branco convencional é a maior produtividade. Para os produtores de algodão Bt, além da produtividade, a redução do uso de agrotóxicos é um dos principais motivos da escolha.

Para avaliar a aceitação de sistemas alternativos de cultivo, um conjunto de opções foi fornecido aos produtores, pedindo que esses ordenassem suas preferências. A análise das preferências declaradas revela que os produtores estão mais propensos a continuar cultivando os próprios sistemas de produção ou sementes que já cultivam. Esses resultados sugerem a existência de inércia, que estaria associada ao custo de mudança e às redes de influência sobre os sistemas de cultivo. A cadeia produtiva, principalmente o papel das cooperativas locais e das redes privadas de apoio à produção e à comercialização, teria um papel decisivo na definição de redes de influência e na adoção de determinado tipo tecnologia. Suri (2011), por exemplo, destaca como a intervenção governamental na distribuição de fertilizantes interfere na adoção de sementes híbridas no Quênia, independente da influência do preço relativo das sementes.

Deve-se também destacar que, no modelo, foram testados diferentes valores de royalties para os sistemas certificados RR e Bt. No entanto, o royalty cobrado não se mostrou significativo na escolha dos produtores da amostra. Em outras palavras, não haveria diferenças de utilidade em relação aos preços de royalty para as sementes certificadas, o que se explica pela adequação entre as necessidades do sistema tecnológico e o papel cumprido pelo tipo de semente. A pouca influência do algodão RR (tolerante ao herbicida) se explica pelas pequenas áreas de cultivo, 
mesmo no grupo mais tecnificado (na análise das preferências reveladas). Como as sementes não são empilhadas, a escolha se volta para o grupo $\mathrm{Bt}$, independente da influência dos royalties no custo da semente. Coerentemente, as diferenças de utilidade existem ao se comparar sementes certificadas e piratas. Finalmente, deve-se considerar a dificuldade de percepção dos custos associados aos royalties para muitos produtores que usualmente recebem as sementes gratuitamente de instituições locais.

De maneira geral, os resultados destacam que o conhecimento do sistema de cultivo, através da prática agrícola corrente, é um fator fundamental nas preferências declaradas dos produtores. O acompanhamento qualitativo das entrevistas também revelou elevada incerteza dos produtores em relação aos novos produtos, seja em relação aos custos de mudança, seja em relação à aceitação e preços a serem pagos pelos intermediários. Neste contexto de incertezas para o pequeno produtor, a orientação de instituições locais seria fundamental, provendo informações para que esses produtores possam avaliar melhor as alternativas de produção.

\section{Referências}

ABEBE, G. K. et al. Adoption of improved potato varieties in Ethiopia: The role of agricultural knowledge and innovation system and smallholder farmers' quality assessment. Agricultural Systems, v. 122 , p. 22-32, 2013.

ALEXANDER, C. E. e VAN MELLOR, T. Determinants of corn rootworm resistant corn adoption in Indiana. AgBioForum, v. 8, p. 197-204, 2005.

ALLISON, P. D. e CHRISTAKIS, N. A. Logit models for sets of ranked items. Sociological Methodology, v. 24, p. 199-228, 1994.

ARAÚJO FILHO, A. A. et al. Caracterização da cadeia produtiva do algodão no semiárido nordestino. Fortaleza, CE: Banco do Nordeste do Brasil, 2012.

ARZA, V. e ZWANENBERG, P. Oportunidades y obstáculos para tecnologías alternativas: el caso del algodón agroecológico en Argentina. CENIT, documento de trabalho, 26p. 2013
., GOLDBERG, L. e VAZQUEZ, C. Argentina: dissemination of genetically modified cotton and its impact on the profitability of small-scale farmers in the Chaco province. CEPAL Review, n. 107, p. 127-143, 2012.

BARRET, C. B. On price risk and the inverse farm size-productivity relationship. Journal of Development Economics, v. 51, p. 193-215, 1996.

BELTRÃO, N. E. M. e CARVALHO, L. P. Algodão colorido no Brasil, e em particular no Nordeste e no Estado da Paraíba. Empresa Brasileira de Pesquisa Agropecuária - Centro Nacional de Pesquisa de Algodão. Documentos 128, 2004.

BOSSLE, M. B. et al. O comércio justo como agente mitigador das mudanças climáticas: o caso do algodão ecológico. Revista contemporânea de Economia e Gestão, v. 10, 2012.

BREUSTEDT, G., MULLER-SCHEEBEL, J. e LATACZLOHMANN, U. Forecasting the adoption of GM oilseed rape: Evidence from a discrete choice experiment in Germany. Journal of Agricultural Economics, v. 59, p. 237256, 2008.

BUAINAIN, A. M. e BATALHA, M. O. Cadeia Produtiva do Algodão. Serie Agronegócios, v. 4, MAPA, SPA-IICA, 107p, 2007.

CUADRAS, C. M. Métodos de análisis multivariante. Barcelona: EUNIBAR - Editorial Universitária de Barcelona S. A., 1981.

DIEDEREN, P. et al. Innovation adoption in agriculture: innovators, early adopters and laggards. Cabiers d'economie et sociologie rurales, v. 67, 2003.

EMBRAPA. Cultura do algodão no cerrado. Sistemas de Produção - Embrapa Algodão, n. 2, 2003.

FELEKE, S. e ZEGEYE, T. Adoption of improved maize varieties in southern Ethiopia: factors and strategy options. Food Policy, v. 31, p. 442-457, 2005.

FERNANDEZ-CONEJO, J., DABERKOW, S. e McBRIDE, W. D. Decomposing the size effect on the adoption of innovations: Agrobiotechnology and Precision Agriculture. AgBioForum, v. 4, p. 124-136, 2001.

GEROSKY, P. A. Models of technology diffusion. Research Policy, v. 29, p. 603-625, 2000.

GONÇALVES, J. S. e RAMOS, S. F. Algodão Brasileiro 1985-2005: surto de importação desencadeia mudanças estruturais na produção. Informações Econômicas, v. 38, p. 54-64, 2008.

GONZÁLES, C., JOHNSON, N. e QAIM, M. Consumer acceptance of second-generation GM foods: the case of biofortified cassava in the North-east of Brazil. Journal of Agricultural Economics, v. 60, p. 604-624, 2004. 
GREENACRE, M. J. Theory and application of correspondence analysis. London: Academic Press Inc, 1984.

e HASTIE, T. The geometric interpretation of correspondence analysis. Journal of the American Statistical Association, v. 82, n. 398, p. 437-447, 1987.

GRILICHES, Z. Hybrid corn: an exploration in the economics of technological change. Econometrica, v. 4, 1957.

GUANZIROLI, C. E. Pronaf dez anos depois: resultados e perspectivas para o desenvolvimento rural. Revista de Economia e Sociologia Rural, v. 45, n. 2, p. 301-328, 2007.

HAEBERLIN, I. B. et al. Evaluación econonómica del uso de algodón transgenico en Cordoba, Costa Atlántica Colombiana. LacBiosafety Corpoica, Escuela Colombiana de Ingineria, Relatório Final, 26 p., 2012.

HAYAME Y. e RUTTAN, V. W. Induced innovation in agricultural development. Discussion Paper, n. 3, 1971.

HOFFMANN, D. L. e FRANKE, G. R. Correspondence analysis: graphical representation of categorical in marketing research. Journal of Marketing Research, v. 23, n. 3, p. 213-227, ago. 1986.

HUANG, J. et al. Bt cotton benefits, costs, and impacts in China. AgBioForum, v. 5, n. 4, p. 153-166, 2002.

HUBBEL, B. J., MARRA, M. C. e CARLSON, G. A. Estimating the demand for a new technology: Bt cotton and inseticide policies. American Journal of Agricultural Economics, v. 82, p. 118-132, 2000.

KOLADY, D. E. e LESSER, W. Who adopts what kind of technologies? The case of Bt eggplant in India. AgBioForum, v. 9, p. 94-103, 2006.

LIMA, P. J. B. F. e SOUZA, M. C. M. Produção brasileira de algodão orgânico e agroecológico, 2006.

LOUVIERE, J. J., HENSHER, D. A. e SWAIT, J. D. Stated choice methods: analysis and application. Cambridge University Press, New York, 2000.

MAIA, A. G. e SILVEIRA, J. M. S. Farmers' preferences for genetically modified corn in Brazil: the contribution of latent attitudes. Anais do $41^{\mathrm{o}}$ Encontro Nacional da ANPEC, Foz do Iguaçu, 2013.

QAIM, M. et al. Adoption of Bt cotton and impact variability: Insights from India. Review of Agricultural Economics, v. 28, n. 1, p. 48-58, 2006.

. e TRAXLER, G. Roundup Ready soybeans in Argentina: farm level and aggregate welfare effects. Agricultural Economics, v. 32, n. 1, p. 73-86, 2005.

RAMOS, J. A. Algodão: redes, tecnologia e meio ambiente. Dissertação de Mestrado. Instituto de Economia. Universidade Estadual de Campinas, 2014.
ROGERS, E. M. Diffusion of innovations. New York: The Free Press, 1971.

SCHIFFER, E. Manual Net-Map Toolbox: Influence mapping of social network. International Food Policy Research Institute, 2007, 19p.

SHIYANI, R. L., ASOKAN, M. e BANTILAN M. C. S. Adoption of improved chickpea varieties: KRIBHCO experience in tribal region of Gujarat, India. Agricultural Economics, v. 27, p. 33-39, 2002.

SILVA, M. N. B., ALVES, G. S. e WANDERLEY JÚNIOR, J. S. A. Manejo cultural do algodoeiro agroecológico no semiárido brasileiro. Empresa Brasileira de Pesquisa Agropecuária - Centro Nacional de Pesquisa de Algodão. Circular Técnica 126, 2009.

SILVEIRA, J. M. F. J. et al. Colaboração e competição na pesquisa agrícola brasileira: o caso do melhoramento genético em algodão no Brasil. Relatório de Pesquisa, Red Mercosur, 2013. Disponível em: <http://www. redsudamericana.org/sites/default/files/doc/DT\%20 Red\%20Mercosur\%20-\%20Brasil.pdf>.

SOUZA FILHO, H. M. et al. Condicionantes da adoção de inovações tecnológicas na agricultura. EMBRAPA, Cadernos de Ciência e Tecnologia, v. 28, n. 1, p. 223-255, 2011.

SOUZA, M. C. M. Produção de algodão orgânico colorido: possibilidades e limitações. Informações Econômicas, SP, v. 30, 2000.

SPIELMAN, D. J., KELEMEWORK, D. M. e ALEMU, D. Seed, fertilizer and agricultural extension in Ethiopia: summary of ESSP Working Paper 20, ESSP research note 12, International Food Policy Research Institute (IFPRI), 2012.

SURI, T. Selection and comparative advantage in adoption. Econometrica, v. 79, n. 1, p. 159-209, 2011.

TIMER, P. The agricultural transformation. Handbook of development economics. In: Chenery \& T.N. Srivivasan (ed.), vol. 1, capítulo 8, p. 275-331, 1988.

VIEGAS, I. F. P. Redes de Comércio Justo e Solidário: organização, relações e valores. Tese de Doutoramento, Instituto de Economia, Unicamp, 2012.

VIEIRA FILHO, J. E. R. Difusão Biotecnológica: a adoção de transgênicos na agricultora. IPEA, Texto para Discussão 1937, 37p, 2014.

. e SILVEIRA, J. M. F. J. Mudança tecnológica na Agricultura: uma revisão crítica da literatura e o papel das economias de aprendizado. Revista de Economia e Sociologia Rural, v. 50, n. 4, p. 717-738, 2012.

WRIGHT, B. D. Grand missions of agricultural innovation. Research Policy, v. 41, p. 1716-1728, 2012. 